\title{
Estrutura e distribuição geográfica do rebanho de ovinos Santa Inês no Estado do Piauí
}

\author{
Structure and geographic distribution of the Santa Inês sheep flock in the Piaui state
}

\author{
REGO NETO, Aurino de Araújo ${ }^{1 *}$; SARMENTO, José Lindenberg Rocha ${ }^{2,4}$; \\ SANTOS, Natanael Pereira da Silva ${ }^{1}$; BIAGIOTTI, Daniel ${ }^{1}$; SANTOS, Gleyson Vieira \\ dos $^{3}$; CAMPELO, José Elivalto Guimarães ${ }^{2}$; SENA, Luciano Silva ${ }^{3}$; FIGUEIREDO \\ FILHO, Luiz Antonio Silva ${ }^{1}$
}

\footnotetext{
${ }^{1}$ Universidade Federal do Piauí, Programa de Pós-Graduação em Ciência Animal, Teresina, Piauí, Brasil.

${ }^{2}$ Universidade Federal do Piauí, Centro de Ciências Agrárias, Departamento de Zootecnia, Teresina, Piauí, Brasil.

${ }^{3}$ Universidade Federal do Piauí, Programa de Pós-Graduação em Zootecnia, Bom Jesus, Piauí, Brasil.

${ }^{4}$ Pesquisador do CNPq.

*Endereço para correspondência: aurinorego@hotmail.com
}

\section{RESUMO}

Objetivou-se descrever o quantitativo, distribuição e estrutura do rebanho de ovino da raça Santa Inês no estado do Piauí. Foram analisados dados de registros genealógicos da raça Santa Inês, mantidos pela Associação Brasileira de Criadores de Ovinos (ARCO), referentes ao período de 1992 a 2012. Foram realizadas análises estatísticas descritivas de modo a conhecer como o rebanho Santa Inês está estruturado. Foi realizada a classificação do rebanho quanto a sua estrutura organizacional, determinada com base na origem e uso dos reprodutores, utilizando-se o programa ENDOG. v.4.8. O registro dos animais da raça Santa Inês, no Piauí, teve inicio em 1990, e a maior representatividade foi verificada no período de 1993 a 2001. Quanto à estrutura dos rebanhos, $56,8 \%$ foram classificados como rebanhos multiplicadores (estrato intermediário da pirâmide) e $43,2 \%$ como rebanhos comerciais (base da pirâmide), sendo que não se observou nenhum rebanho núcleo e nem isolado. A falta de rebanhos núcleo da raça no Estado pode ser uma das causas da redução do número de animais registrados nos últimos anos no Piauí.

Palavras-chave: estrutura organizacional, ovinocultura de corte, ovinos deslanados, raças nativas

\section{SUMMARY}

This study aimed to describe the quantity, distribution and structure of the Santa Inês sheep flock in the Piauí state. We analyzed data of genealogical records of Santa Inês variety, maintained by the Brazilian Association of Breeders Sheep (ARCO), from 1992 to 2012. Descriptive statistical analyzes were performed in order to know how the Santa Inês herd is structured. We classified the herd according to its organizational structure, determined according to the origin and the use of the breeders, using the program ENDOG.v.4.8. The registration of animals of Santa Ines variety, in Piauí, started in 1990, and highest representation was verified in the period from 1993 to 2001 . As for the structure of the herds, $56.8 \%$ were classified as multiplying livestocks (intermediate stratum of the pyramid) and $43.2 \%$ as commercial herds (base of the pyramid), and there was neither nucleus nor isolated herds. The lack of nucleus herds of Santa Inês variety in the state may be one of the causes of the reduction in the number of animals recorded in recent years in Piauí.

Keywords: beef sheep, hair sheep, native breeds, organizational structure 


\section{INTRODUÇ̃̃̃O}

A procura por carne ovina vem crescendo consideravelmente no Brasil, sendo que a demanda mostra-se superior à oferta. Para atender o mercado e manter o crescimento do agronegócio, é necessário que a produção de cordeiros atenda a demanda e seja constante ao longo do ano.

A região Nordeste é detentora de um efetivo de 9,56 milhões de cabeças de ovinos, o que corresponde a $57,24 \%$ do rebanho brasileiro. O Estado do Piauí ocupa o quinto lugar no ranking nacional e é o quarto do Nordeste com aproximadamente 7,91\% (IBGE, 2011). Todavia, apesar da potencialidade da ovinocultura no Piauí, ainda não existem programas de melhoramento genético estruturados com esta espécie, no entanto, fica o melhoramento genético de ovinos, mais na dependência da tenacidade de poucos pesquisadores e criadores, como ocorre também no Nordeste (CARNEIRO et al., 2006), ou importação de reprodutores de outros Estados e Países.

A forma mais eficiente para garantir o sucesso da produção de carne, de modo geral, é por meio da organização dos rebanhos em três estratos, formando uma estrutura tipicamente piramidal, em que pequena proporção, o ápice da pirâmide, representa os chamados rebanhos núcleos, nos quais se realiza o melhoramento genético por intermédio da seleção, e os animais geneticamente produzidos neste estrato são disseminados para a maioria dos criadores (rebanhos comercias), ou seja, a base da pirâmide. Os multiplicadores, estrato intermediário, são aqueles produtores que praticam pouca ou quase nenhuma seleção, mas que, por adquirirem animais do núcleo, possuem rebanhos de razoável qualidade genética e, por isso, vendem animais para reprodução, quer sejam puros ou cruzados (ALVES et al.,1999).

No entanto, a "pirâmide" de estrutura de raças ovinas no Brasil tem na verdade a forma de uma "moringa, ou seja, a passagem do progresso genético dos rebanhos de elite para os rebanhos comerciais fica estrangulada nos rebanhos multiplicadores" (MORAIS, 2001). Entretanto, desde então não foi verificado na literatura nenhum estudo que avaliasse essa estrutura proposta para ovinocultura brasileira.

Neste contexto, objetivou-se com este artigo descrever o quantitativo, a distribuição geográfica e a estrutura organizacional do rebanho de ovinos da raça Santa Inês no estado do Piauí.

\section{MATERIAL E MÉTODOS}

Os dados utilizados foram provenientes de registro genealógico da raça Santa Inês, disponíveis sob processamento eletrônico, da Associação Brasileira de Criadores de Ovinos (ARCO), referentes ao estado do Piauí, no período de 1992 a 2012. O arquivo de dados foi gerado com as informações referentes a cada animal constante das informações de pai, mãe, sexo, data de nascimento, criador e município, totalizando um arquivo com 20.206 animais.

As análises foram realizadas no Laboratório de Melhoramento Genético e Análise de Dados da Universidade Federal do Piauí, Campus Universitário Professora Cinobelina Elvas, em Bom Jesus, Piauí.

O banco de dados foi editado por ano, em cada ano foi calculado o número de animais registrados e o número de produtores com registros, os quais foram classificados por mesorregiões do estado do Piauí. 
A classificação do rebanho, quanto a sua estrutura organizacional foi realizada com base na origem e uso dos reprodutores, em que os rebanhos foram classificados como rebanhos Núcleo (rebanhos que não utilizam reprodutores externos e repassam reprodutores para outros rebanhos), Multiplicador (considerados como rebanhos que utilizam reprodutores externos ou próprios e repassam reprodutores para outros rebanhos), Comercial (definidos como rebanhos que utilizam reprodutores externos ou próprios e não repassam reprodutores para outros rebanhos) e rebanho Isolado (considerados como rebanhos que não recebem e nem repassam reprodutores comprados, nem vende reprodutores). As analises permitiram avaliar como o rebanho está distribuído de acordo com a estrutura piramidal da produção de ovinos Santa Inês, com auxilio do Software ENDOG. v.4.8 (GUTIÉRREZ \& GOYACHE, 2005).

Foi avaliada a distribuição do rebanho por mesorregiões, em que o Estado é dividido: Centro Norte, Norte, Sudeste e Sudoeste.

Para melhor entendimento da distribuição dos animais no Estado realizou-se análise dos dados por meio de estatísticas descritivas com os animais registrados estratificados por ano e por mesorregião e analises com o número de produtores que registram animais na ARCO.

\section{RESULTADOS E DISCUSSÃO}

O registro de animais da raça Santa Inês, no estado do Piauí, teve início em 1990, sendo que a maior representatividade foi verificada no período de 1993 a 2001, que passou de pouco mais de 200 registros, no ano de
1993, para mais de 2.200 registros, no ano de 2001. No entanto, no período compreendido entre os anos de 2001 e 2012, o número de animais registrados apresentou decréscimo significativo de mais de 2.200 animais registrados, no ano de 2001, para pouco mais de 100 registros, no ano de 2012 (Figura 1).

Este comportamento se deve ao modismo que acontece na ovinocultura. Raças surgem, passam a ser utilizadas intensivamente, mesmo sem avaliação genética adequada, posteriormente deixam de ser utilizadas e passam a correr risco de extinção, necessitando assim de programas de conservação genética e medidas objetivas que visem sua utilização futura (CARNEIRO et al., 2009).

Em relação à raça Santa Inês o que foi observado não é diferente, os criadores despertaram o interesse pela raça em função do porte, da velocidade de crescimento e da alta adaptabilidade aos trópicos, porém, a desorganização da cadeia produtiva da raça, com falhas na comercialização e no direcionamento da criação, onde a grande maioria dos criadores direcionou suas criações pensando apenas nas exposições e leilões, ou seja, compra de campeões para venda de seus filhos. Neste sentido, a seleção era praticada apenas com o intuito de padronizar a raça, considerando na maioria das vezes apenas o exterior (fenótipo) sem se preocupar com desempenho produtivo e reprodutivo da raça, o que pode ter provocado com o passar do tempo, a substituição da raça Santa Inês por raças exóticas mais produtivas, ou da moda, ou a utilização das raças exóticas em esquemas de cruzamento absorvente para obter mestiços mais produtivos. Estes fatos podem justificar a redução drástica no número de registros de animais da raça no Estado do Piauí. 


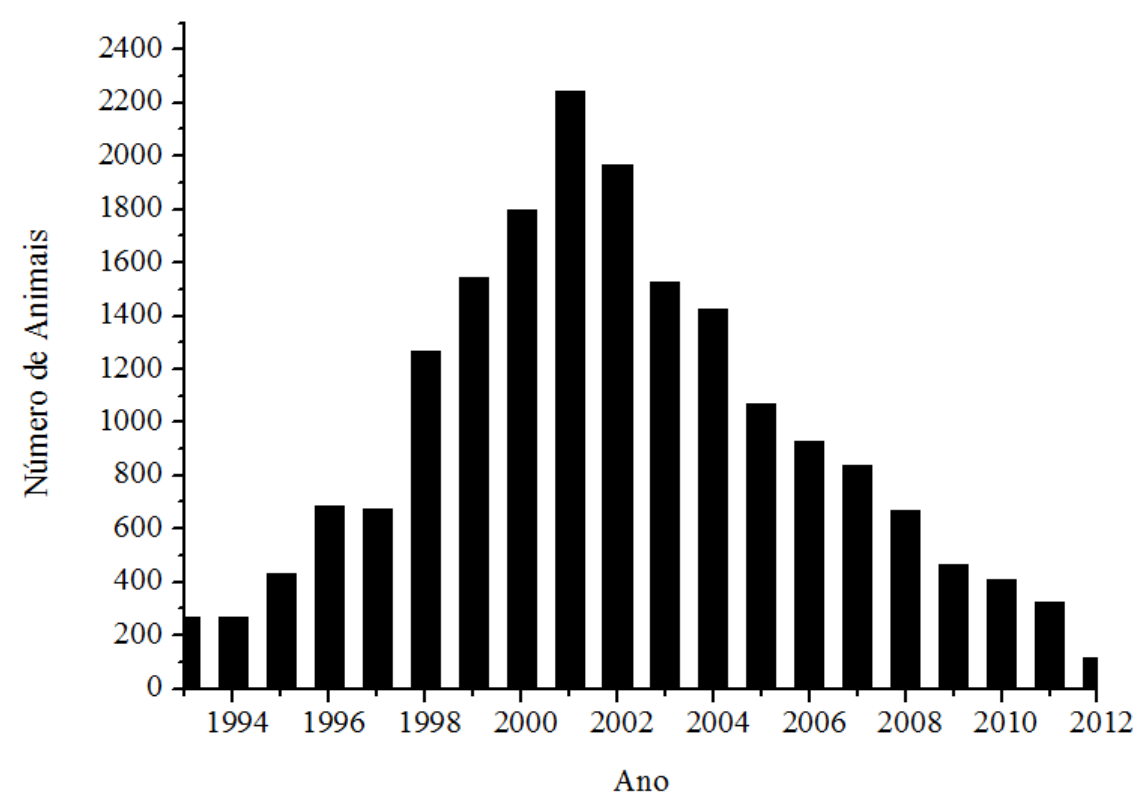

Figura 1. Distribuição de animais da raça Santa Inês registrados na Associação Brasileira de Criadores de Ovinos (ARCO) por ano de nascimento, no estado do Piauí

Por se tratar do Estado com o quinto maior rebanho de ovinos do Brasil, este resultado contradiz o que alguns autores (CARNEIRO et al. 2006; SANTOS, 2007) pregam sobre a situação da raça no país, a qual é tida como a raça com maior aceitação nos últimos anos pelos criadores de ovinos para produção de carne, chegando a ser comparada com a raça de bovinos Nelore.

De acordo com Egito et al. (2002), a busca por raças mais produtivas fez com que, a partir do final do século XIX e início do século XX, houvesse importações de raças consideradas exóticas que, embora fossem altamente produtivas, haviam sido selecionadas em regiões de clima temperado e não apresentavam características de resistência das raças locais. Estas raças, por cruzamentos absorventes, causaram rápida substituição e erosão nas raças locais, de tal maneira que essas, atualmente, encontram-se em risco de extinção. As raças nativas apresentam níveis de produção mais baixos, quando comparado às exóticas na sua origem, mas se distinguem das raças importadas por estarem totalmente adaptadas aos trópicos, onde sofreram longa seleção natural.

A ovinocultura passa por transformações desde a década de 1990. Os rebanhos começaram a ser explorados economicamente com a introdução de raças especializadas, melhoramento genético e técnicas de manejo que propiciaram o aumento da produtividade (VIANA, 2008).

No que diz respeito à classificação do rebanho piauiense, quanto a sua estrutura, $56,8 \%$ dos rebanhos foram classificados como multiplicador (estrato intermediário da pirâmide) e 43,2\% como rebanho comercial (base da pirâmide), não apresentando nenhum rebanho núcleo (ápice da pirâmide) e nem isolado (Tabela 1).

A falta de rebanhos núcleo implica em ausência de melhoramento genético da raça no Estado e, em consequência, menor desempenho produtivo e menor 
retorno econômico aos criadores, o que pode ter contribuído para a substituição da raça por raças exóticas já melhoradas geneticamente para produção de carne. Rebanhos núcleo ou de elite são os de maior qualidade genética, tendo como condição essencial para seu êxito, um intenso trabalho de seleção realizado de forma permanente, com objetivo de produzir animais de genética superior para características produtivas, reprodutivas e de conformação. Nestes rebanhos, o trabalho de seleção deve ser subsidiado por programas de melhoramento genético que permitam a utilização de metodologias modernas de avaliação genética, de modo a identificar com exatidão os animais geneticamente superiores.

Tabela 1. Critério de classificação dos rebanhos de ovinos da raça Santa Inês registrados no estado do Piauí, de acordo com a origem e uso dos reprodutores

\begin{tabular}{lccccc}
\hline Tipo de rebanho & $\begin{array}{c}\text { Utilizam } \\
\text { reprodutores } \\
\text { externos }\end{array}$ & $\begin{array}{c}\text { Utilizam } \\
\text { próprios } \\
\text { reprodutores }\end{array}$ & $\begin{array}{c}\text { Repassam } \\
\text { reprodutores }\end{array}$ & $\begin{array}{c}\text { Números de } \\
\text { rebanhos }\end{array}$ & $\begin{array}{c}\text { Rebanhos } \\
(\%)\end{array}$ \\
\hline Núcleo & Não & Sim & Sim & 0 & 0 \\
Multiplicador & Sim & Sim & Sim & 45 & 55,56 \\
Multiplicador & Sim & Não & Sim & 1 & 1,23 \\
Comercial & Sim & Sim & Não & 18 & 22,23 \\
Comercial & Sim & Não & Não & 17 & 20,98 \\
Isolado & Não & Sim & Não & 0 & 0 \\
\hline
\end{tabular}

Em concordância com o que foi observado neste trabalho, Carneiro et al. (2006), afirmaram que no estado do Piauí, onde se encontra um dos maiores rebanhos do Nordeste e a raça Santa Inês se destaca, não existe programa aprimorado de melhoramento genético para esta raça e nem para a espécie ovina, estando o melhoramento genético nos ovinos associado à tenacidade de poucos pesquisadores e criadores.

A partir dos resultados verificados observou-se que a falta de rebanhos núcleo, o grande número de rebanhos multiplicador e o pequeno número de rebanhos comercial implicaram em uma pirâmide sem ápice e de base estreita, resultando em maior custo por animal (Figura 2).

O grande número de rebanhos Multiplicador pode ser justificado pelo fato da maioria dos criadores ocupantes deste estrato, se preocupar apenas em produzir animais vencedores de exposições para participação em leilões, em virtude da supervalorização dos animais premiados em maior número de eventos.

Por não existirem rebanhos núcleos (rebanhos que praticam de fato seleção genética), não existe fluxo gênico para o estrato intermediário da pirâmide, isto implica que parte dos reprodutores utilizados para reprodução é adquirida de outros rebanhos, o que acaba gerando um ciclo vicioso dentro deste estrato, onde a referência de animais de genética superior passa a ser apenas os julgamentos subjetivos praticados em exposições. Em função deste comportamento, criadores de animais multiplicadores utilizam rodízio entre os reprodutores dessa classe, com pequeno 
fluxo gênico (baixo número de reprodutores) para o estrato comercial, em consequência do alto custo dos animais, fazendo com que o melhoramento genético de ovinos no estado do Piauí não se desenvolva conforme a literatura preconiza, seguindo a estrutura de "pirâmide".

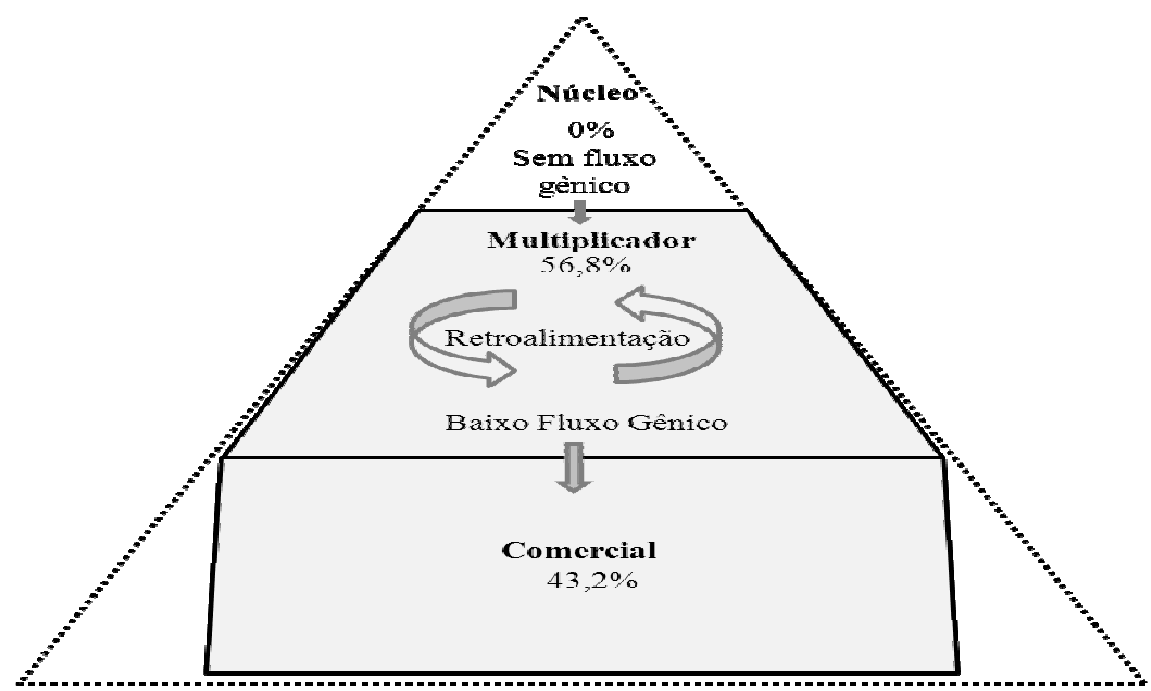

Figura 2. Estrutura piramidal de organização da produção de carne, estratificada em rebanhos núcleos, multiplicadores e comerciais do rebanho de ovinos Santa Inês registrados no estado do Piauí

A estrutura de organização da produção de carne da raça Santa Inês no estado do Piauí não segue a estrutura piramidal proposta por Alves et al. (1999), em que pequena proporção, o ápice da pirâmide, representa os chamados rebanhos núcleos, nos quais se realiza o melhoramento genético por intermédio da seleção e os animais geneticamente produzidos neste estrato são disseminados para a maioria dos criadores (rebanhos comercias), ou seja, a base da pirâmide. Os multiplicadores, estrato intermediário, são aqueles produtores que praticam pouca ou quase nenhuma seleção, mas que, por adquirirem animais do núcleo, possuem rebanhos de razoável qualidade genética e, por isso, vendem animais para reprodução, quer sejam puros ou cruzados.

A estrutura organizacional da produção de carne encontrada no Piauí para a raça
Santa Inês pode ser representada por uma pirâmide de base estreita e sem topo (ápice), conforme representado na Figura 2. A linha pontilhada representa a estrutura apresentada por Alves et al. (1999) e as linhas contínuas representam a estrutura verificada atualmente no estado, ou seja, ausência de rebanhos núcleos (rebanhos melhoradores) e com rebanho multiplicador, que na grande maioria das vezes é confundido com rebanhos núcleos ou chamado de elite, maior que o rebanho comercial, por isso não verificando a estrutura piramidal.

A estrutura reforça a teoria que a maioria dos criadores direciona seus rebanhos para venda de reprodutores e adquirem seus reprodutores de outros rebanhos deste estrato, o que gera um fluxo gênico dentro deste estrato, o que foi chamado por Morais (2001) de retroalimentação, ou seja, troca de 
reprodutores entre os rebanhos do mesmo estrato. Esse processo gera pouco ou nenhum progresso genético uma vez que os criadores multiplicadores fazem pouca ou nenhuma seleção.

A estrutura organizacional do rebanho Santa Inês no Estado do Piauí verificada neste estudo representa mais um hexágono não regular do que a estrutura piramidal, estrutura ideal quando se pensa em melhoramento genético de uma raça. Neste sentido, esse problema pode ser um dos grandes entraves do melhoramento genético do Piaú, a falta de organização da cadeia produtiva de modo que a população estivesse representada nos três estratos da pirâmide. $\mathrm{O}$ mais preocupante é que o estrato com ausência de rebanhos é o mais importante do ponto de vista do melhoramento genético, pois é nesse estrato que se pratica seleção.

Em contrapartida, Morais (2001) sugeriu que a estrutura organizacional dos ovinos no Brasil tinha forma de "moringa", sendo que os animais que compõem os rebanhos elite (núcleo) tem custo elevado e não chegam ao estrato dos rebanhos comerciais por ineficiência dos rebanhos que compõem o estrato multiplicador. Assim, os animais melhoradores pertencentes ao estrato núcleo tendem a circular entre rebanhos deste mesmo estrato.

A sugestão de Morais (2001) para os rebanhos elite (núcleo) com relação à retroalimentação dos reprodutores nos rebanhos elite foi identificada no rebanho do Estado do Piauí, no estrato multiplicador, uma vez que a metodologia empregada não identificou rebanhos com perfil de núcleo. Os rebanhos que compõem o estrato multiplicador da pirâmide diferem em parte da proposta de Morais (2001), principalmente no que se refere ao tamanho, uma vez que para a população estudada foi o maior estrato verificado, maior inclusive do que o comercial. Todavia, pode-se imaginar que os rebanhos deste estrato ainda passam por problemas como os apresentados por Morais (2001), ineficiência reprodutiva, custo elevado dos reprodutores e baixo fluxo gênico dos rebanhos multiplicadores para os comerciais, ou seja, a maior parte dos reprodutores produzidos pelos rebanhos multiplicadores tende a circular entre os rebanhos deste mesmo estrato da pirâmide.

Diante deste cenário, ações imediatas precisam ser tomadas de modo que a cadeia produtiva seja mais bem trabalhada e a estrutura piramidal para produção de carne ovina no Piauí seja implantada, o que permitirá, de fato, realizar melhoramento genético desta raça.

A distribuição dos produtores de ovino Santa Inês que fazem registro genealógico na Associação Brasileira de Criadores de Ovinos (ARCO) no Piauí, por mesorregião, no período de 1992 a 2010 se comportou de maneira semelhante à distribuição do rebanho, ou seja, grande concentração de produtores na mesorregião do Centro Norte piauiense (Tabela 2).

Nos anos de 2011 e 2012, pode-se observar redução no número de produtores em todas as mesorregiões do estado, em relação aos anos anteriores, com destaque para as mesorregiões Sudeste e Norte as quais não apresentaram nenhum produtor com registro de ovinos Santa Inês, junto a Associação Brasileira de Criadores de Ovinos (ARCO) (Tabela 2). Este comportamento pode ser reflexo do uso da raça em cruzamentos com raças exóticas ou da substituição total da raça por raças exóticas, ocasionado pelo modismo de raças, substituição pela raça em alta no mercado de venda de reprodutores em leilões e exposições. 
Rev. Bras. Saúde Prod. Anim., Salvador, v.15, n.2, p.272-280 abr./jun., 2014 http://www.rbspa.ufba.br ISSN 15199940

Tabela 2. Distribuição dos produtores de ovinos Santa Inês com registro na Associação Brasileira de Criadores de Ovinos (ARCO) por mesorregião do estado do Piauí

\begin{tabular}{lcc}
\hline \multirow{2}{*}{ Mesorregião } & \multicolumn{2}{c}{ Período } \\
\cline { 2 - 3 } & $1992-2010$ & $2011-2012$ \\
\hline Centro Norte & 77 & 7 \\
Norte & 9 & 0 \\
Sudoeste & 7 & 1 \\
Sudeste & 2 & 0 \\
\hline
\end{tabular}

Segundo Rodrigues et al. (2009), as raças nativas estão sob forte ameaça, causada principalmente, pelos cruzamentos desordenados com reprodutores de raças exóticas, frequentemente utilizados como estratégia de modernização dos sistemas de produção.

A falta de rebanhos núcleo da raça no Estado pode ser uma das causas responsáveis pela redução do número de animais registrados nos últimos anos no Piauí.

O rebanho de ovinos Santa Inês registrados do Piauí encontra-se em maior concentração nas mesorregiões Centro Norte e Norte, porém com número de animais registrados diminuindo ao longo dos anos.

Ações imediatas necessitam ser implantadas para incrementar $\mathrm{o}$ crescimento da raça no estado de forma a reorganizar a estrutura piramidal da população para produção de carne ovina.

\section{AGRADECIMENTOS}

À Associação Brasileira de Criadores de Ovinos (ARCO) pela concessão do banco de dados.

\section{REFERÊNCIAS}

ALVES, R.G.O.; SILVA, L.O.C.; EUCLIDES FILHO, K.;

FIGUEIREDO, G.R. Disseminação do melhoramento genético em bovinos de corte. Revista Brasileira de Zootecnia, v.28, n.6, p.1219-1225, 1999.

CARNEIRO, P.L.S.; MALHADO, C.H.M.; AZEVÊDO D.M.M.R.; SOUZA, L.G.R.; SILVA, D.C.; ALVES, A.Z.; CAMPELO, J.E.G.; COSTA JÚNIOR, G.S. Estudo de populações de ovinos Santa Inês utilizando técnicas de análise multivariada. Revista Científica de Produção Animal, v.8, n.1, p.40-50, 2006.

CARNEIRO, P.L.S.; MALHADO

C.H.M.; MARTINS FILHO R.; CARNEIRO A.P.S.; SILVA F.F.; TORRES R.A. A raça Indubrasil no Nordeste brasileiro: melhoramento e estrutura populacional. Revista Brasileira de Zootecnia, v.38, n.12, p.2327-2334, 2009.

EGITO, A.A.; MARIANTE, A.S.; ALBUQUERQUE, M.S.M. Programa brasileiro de conservação de recursos genéticos animais. Archivos de Zootecnia, v.51, n.193-194, p.39-52, 2002.

GUTIÉRREZ, J.P.; GOYACHE, F. A note on ENDOG: a computer program for analyzing pedigree information. Journal of Animal Breeding and Genetics, v.122, p.172- 176, 2005.

INSTITUTO BRASILEIRO DE GEOGRAFIA E ESTATÍSTICA IBGE. Pesquisa Pecuária Municipal. 2011. Disponível em: $<$ http://www.sidra.ibge.gov.br/cgi-bin.> Acesso em: 20 nov. 2012. 
Rev. Bras. Saúde Prod. Anim., Salvador, v.15, n.2, p.272-280 abr./jun., 2014 http://www.rbspa.ufba.br ISSN 15199940

MORAIS, O.R.O. Melhoramento genético dos ovinos no Brasil: Situação atual e perspectivas para o futuro. In: SIMPÓSIO DA SOCIEDADE BRASILEIRA DE MELHORAMENTO ANIMAL, 3., 2001, Uberaba. Anais... Uberaba: Sociedade Brasileira de Melhoramento Animal, 2001. p.266272.

RODRIGUES, D.S.; RIBEIRO, M.N.; OLIVEIRA, S.M.P.; LIMA, F.A.M.; VILLARROEL, A.B.S.; PACHECO, A.C.L.; SANTOS, L.H. Estrutura populacional de um rebanho da Raça Morada nova como contribuição para a conservação. Ciência Animal, v.19, n.1, p.103-110, 2009.
SANTOS, R. Santa Inés: the Brazilian prime sheep. Uberaba, MG:

Agropecuária Tropical, 2007.

VIANA, J.G.A. Panorama geral da ovinocultura no mundo e no Brasil. Revista Ovinos, v.4, n.12, 2008.

Data de recebimento: 11/02/2014

Data de aprovação: 28/05/2014 